\title{
The Mechanism and Performance of Zeolites for Ammonia Removal in the Zeolite Packed Electrolysis Reactor
}

\section{Yuanxing HUANG, Cuihong SONG, Liang LI, ${ }^{*}$ and Yuemei ZHOU}

\author{
School of Environment and Architecture, University of Shanghai for Science and Technology, \\ No. 516 Jungong Road, Shanghai, P. R. China
}

\section{*Corresponding author: liliang@usst.edu.cn}

\begin{abstract}
Electrolytic removal of ammonia was investigated by using zeolite packed electrolysis reactor in batch mode. The results showed that $27.8 \mathrm{mg} \mathrm{N} / \mathrm{L}$ ammonia could be removed to a concentration as low as $0.3 \mathrm{mg} \mathrm{N} / \mathrm{L}$ within $1 \mathrm{~h}$. Nitrite, nitrate and chloramines were determined to be $0.02 \mathrm{mg} \mathrm{N} / \mathrm{L}, 3.9 \mathrm{mg} \mathrm{N} / \mathrm{L}$ and $15.8 \mathrm{mg} \mathrm{Cl} / \mathrm{L}$, respectively, which accounted for a total nitrogen removal of $80 \%$ after $1.5 \mathrm{~h}$ of electrolysis. The main components and crystalline structure of the packed zeolite were found to be unchanged after long time of electrolysis. The specific surface area and pore volume of zeolite increased from $15.9 \mathrm{~m}^{2} / \mathrm{g}$ and $0.05 \mathrm{~cm}^{3} / \mathrm{g}$ to $42.6 \mathrm{~m}^{2} / \mathrm{g}$ and $0.08 \mathrm{~cm} / \mathrm{g}$, respectively, which might be caused by the removal of impurities and formation of new channels and cavities during electrolysis. The adsorption capacities of zeolite for ammonia before and after electrolysis were close.
\end{abstract}

(c) The Electrochemical Society of Japan, All rights reserved.

Keywords : Electrochemical Oxidation, Ammonia, Zeolite, Adsorption

\section{Introduction}

As one of the main nitrogenous contaminants, nowadays ammonia is frequently detected in industrial, agriculture, municipal wastewaters and landfill leachate., ${ }^{1,2}$ Oxygen depletion and algae blooming are common phenomena occurred when large amount of ammonia is released into surface water, which will accelerate the eutrophication process of estuaries, lake or coastal seas. Therefore removal of ammonia from wastewater is a critical issue especially in sensitive and fragile area.

Methods including nitrification/denitrification, chemical precipitation, air stripping, ion-exchange, photocatalytic oxidation and plasma treatment are available for ammonia removal from wastewater. ${ }^{3-8}$ Among them, air stripping process is usually effective for wastewater with high ammonia concentration. Biodegradation is a preferable choice to treat municipal sewage with low ammonia concentration and low toxicity under mesophilic temperature. Chemical precipitation usually produces large amount of chemical sludge that is difficult to handle. Photocatalytic oxidation and plasma treatment of ammonia is usually more effective in alkaline solution since hydroxyl radical reacts fast with $\mathrm{NH}_{3}$ instead of $\mathrm{NH}_{4}{ }^{+}$.

In term of ion exchange or adsorption, zeolite was proved to have high cation exchange capacity and great affinity for ammonia compared with other natural materials. ${ }^{9-11}$ According to Halim and his co-workers, ${ }^{12}$ ammonia adsorption capacity of zeolite can reach up to $17.5 \mathrm{mg} \mathrm{N} / \mathrm{g}$, and activated carbon is only $6.1 \mathrm{mg} \mathrm{N} / \mathrm{g}$. In addition, zeolite adsorption was preferred by many researchers due to its easy operation, low cost and independence of temperature. Accordingly, regeneration of saturated zeolite by biological or chemical means is a hot research area. Lei et al. proved that saturated zeolite can be regenerated using electrochemical method and the adsorption capacities of regenerated zeolite were almost the same as unused zeolite. ${ }^{13}$

Strong oxidants such as hydroxyl radicals, hypochlorite acid etc. generated during electrochemical oxidation process can oxidize various pollutants in wastewater. For traditional two dimensional (2D) electrode reactor, area-volume ratio, mass transfer and current efficiency were the main limitations for its wide application.
Therefore three dimensional (3D) electrode was developed to overcome these shortcomings. In recent years, 3D electrode reactors had been successfully applied to the treatment of landfill leachate, tannery wastewater, textile wastewater etc. ${ }^{14-16}$ Granular activated carbon (GAC) was often used as particle electrode in many researches due to its large surface area, high adsorption capacity for various organic compounds and catalytic properties within electric field, which had been successfully applied to the treatment of phenol, ${ }^{17}$ acid orange $7,{ }^{18}$ p-nitrophenol ${ }^{19}$ etc. Apart from GAC, modified kaolin was successfully prepared and used as packed bed particle electrode for removal of anionic surfactants by Kong et al. ${ }^{20}$ Foaming nickel was also investigated as the particle electrode by Liu et al., which showed high removal efficiency (99\%) for rhodamine $\mathrm{B}$ at neutral $\mathrm{pH}$ in 30 mins. $^{21}$

Compared with activated carbon, zeolite, known as silica-rich heulandite, has great affinity for ammonia. In this research, natural zeolite without any modification was packed in the electrolysis reactor, which provided special large surface area and active sites for ammonia removal from aqueous phase. Mechanism, main products and the change of zeolites' specific characteristics before and after electrolysis were investigated respectively for electrocatalytic ammonia removal by using zeolite packed electrolysis reactor.

\section{Experimental}

\subsection{Set-up and procedure}

Electrochemical experiment was performed in recycling mode at laboratory scale in a cylindrical cell (2) $(62 \mathrm{~mm}$ inner diameter, $248 \mathrm{~mm}$ height) made of stainless steel. $\mathrm{RuO}_{2} / \mathrm{Ti}$ and stainless steel with the same dimension of $176 \times 38 \times 1 \mathrm{~mm}$ were used as anode and cathode, respectively. Natural zeolite (9) was clinoptilolite with diameter of 2-3 mm, which was purchased from Jinyun County, Zhejiang Province, China. The zeolite was packed into the electrolysis reactor, which resulted in a void volume of $350 \mathrm{~mL}$. Anode and cathode were connected to a direct current (DC) power supply (1) (WYJ, Shanghai Wenkai Power Supply Equipment Ltd, China) with maximum output of $10 \mathrm{~A}$ and $30 \mathrm{~V}$. As shown in Fig. 1, wastewater containing ammonia was stocked in feed tank (5), and 


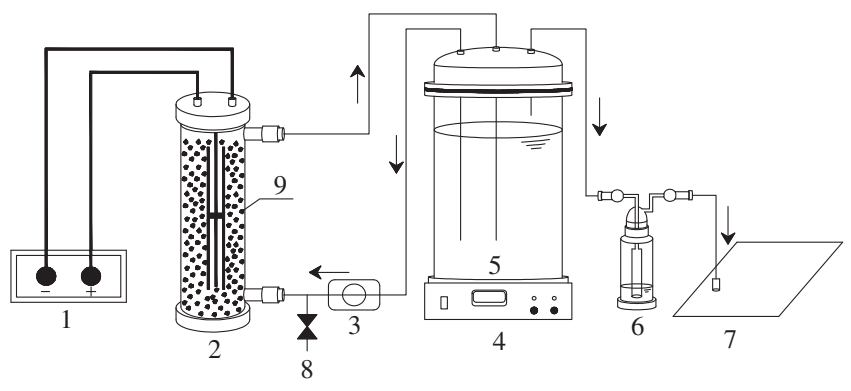

Figure 1. The schematic diagram of zeolite packed electrolysis reactor. 1. DC power supply; 2. electrolytic reactor; 3. peristaltic pump; 4. magnetic stirrer; 5. feed tank; 6. gas washer; 7. gas collector; 8. sampling port; 9. natural zeolite.

pumped by a peristaltic pump (3) (YZ1515X, Baoding Longer Precision Pump Ltd, China) into electrolytic reactor (2) at constant flow rate of $150 \mathrm{~mL} / \mathrm{min}$. Magnetic stirrer was used to mix the solution in order to make homogenous concentration distribution in feed tank. The total volume of aqueous solution in the system is $4 \mathrm{~L}$ so the retention time is 2.3 and $24.3 \mathrm{~min}$ in electrochemical cell and feed tank respectively. In a gas washer (6), boric acid solution was used in order to evaluate the gas stripping contribution for ammonia removal. Water samples were taken from sampling port (8) and analyzed immediately.

\subsection{Chemicals and materials}

The synthetic wastewater was prepared by dissolving analytical reagents into deionized water. The chemicals used in this research were purchased from Sinopharm Chemical Reagent Co., Ltd (Shanghai, China). The composition of the synthetic wastewater was as follows: $\left(\mathrm{NH}_{4}\right)_{2} \mathrm{SO}_{4}, 131 \mathrm{mg} / \mathrm{L} ; \mathrm{NaCl}, 544 \mathrm{mg} / \mathrm{L} .1 \mathrm{~mol} / \mathrm{L}$ $\mathrm{NaOH}$ and $0.5 \mathrm{~mol} / \mathrm{L} \mathrm{H}_{2} \mathrm{SO}_{4}$ were used to adjust the $\mathrm{pH}$ of the synthetic wastewater. In addition, $30 \%$ boric acid was prepared as adsorption solution in the gas washer to determine the volatilization of ammonia.

\subsection{Analysis}

According to standard methods, ${ }^{22}$ ammonia was determined by Nessler method. The analysis of nitrate was done by UV spectrophotometry. Nitrite was analyzed through N-(1-naphthyl)ethylenediamine dihydrochloride spectrophotometric method. Free chlorine (including $\mathrm{HOCl}, \mathrm{Cl}_{2}$ and $\mathrm{ClO}^{-}$) and total chlorine (including free chlorine and chloramines) was determined by DPD ferrous titrimetric method. Chloride ion was measured through titrimetric method with silver nitrate. $\mathrm{pH}$ was measured by a $\mathrm{pH}$ meter (PHS-2C, Leici Company, Shanghai, China). Total nitrogen was measured by a TOC/TN analyzer (Multi N/C 3100, Analytikjena Company, Germany).

$\mathrm{X}$-ray powder diffraction (XRD) of all samples was performed in reflection mode by Bruker D8 Advance X-ray diffractometer under voltage $40 \mathrm{kV}$ and current $30 \mathrm{~mA}$ with a $\mathrm{Cu} \mathrm{K \alpha}$ radiation, which employed a scan rate of $8^{\circ}$ per min in $2 \theta$ ranging from 10 to $50^{\circ}$. Nitrogen adsorption-desorption isotherms were collected on Micromeritics ASAP 2020 surface area and porosity analyzer at $77 \mathrm{~K}$ after the sample had been degassed at $200^{\circ} \mathrm{C}$ for $5 \mathrm{~h}$. The BrunauerEmmett-Teller (BET) surface area was calculated from the linear part of BET plot $\left(\mathrm{P} / \mathrm{P}_{0}=0.04-0.16\right)$. Morphological features of the zeolite before and after electrolytic process were analyzed by a scanning electron microscope (SEM, S4800, Hitachi, Japan).

\section{Results and Discussion}

After experiment, the concentration of ammonia in gas washer was measured and the result showed that ammonia volatilization was less than $1 \%$. So the amount of ammonia removed through volatilization can be ignored.

\subsection{Mechanism of ammonia removal}

Figures 2(a) and 2(b) illustrated the changes of nitrogen and chloro species in water during the electrolysis of ammonia solution with $330 \mathrm{mg} / \mathrm{L} \mathrm{Cl}^{-}$at $\mathrm{pH} 7.0$ and current density $13.8 \mathrm{~mA} / \mathrm{cm}^{2}$, respectively. As shown in Fig. 2(a), concentration of ammonia decreased quickly from $27.8 \mathrm{mg} \mathrm{N} / \mathrm{L}$ to $0.3 \mathrm{mg} \mathrm{N} / \mathrm{L}$ in $1 \mathrm{~h}$. After $1.5 \mathrm{~h}$ of electrolysis, total nitrogen decreased from $30.1 \mathrm{mg} \mathrm{N} / \mathrm{L}$ to $5.8 \mathrm{mg} \mathrm{N} / \mathrm{L}$, and nitrate concentration increased from 0 to $3.9 \mathrm{mg} \mathrm{N} / \mathrm{L}$. Nitrite concentration was always below $0.02 \mathrm{mg} \mathrm{N} / \mathrm{L}$. With regard to the variety of chloride ions, free chlorine and total chlorine, the transformation of element $\mathrm{Cl}$ was shown in Fig. 2(b). The concentration of $\mathrm{Cl}^{-}$decreased from 330 to $300 \mathrm{mg} / \mathrm{L}$ after $1.5 \mathrm{~h}$ of electrolysis of synthetic wastewater. During the same time period, free and total chlorine was detected out in aqueous phase with concentration range of $0-1.3$ and $0-17.1 \mathrm{mg} \mathrm{Cl} / \mathrm{L}$, respectively. Consequently, the reduction of $\mathrm{Cl}^{-}$could be attributed to the formation of total chlorine in water and $\mathrm{Cl}_{2}$ escaped from the solution in gaseous form. The variety of $\mathrm{Cl}^{-}$was in accordance with the results obtained by Rosilda et al. ${ }^{23}$ Moreover, the electrolytic removal of ammonia was effective for both $\mathrm{NH}_{3}$ and $\mathrm{NH}_{4}{ }^{+}$, which was different from the photocatalytic oxidation. ${ }^{8}$ Oxidation by hydroxyl radical was considered to be the main mechanism for ammonia removal in photocatalytic oxidation, which was more effective in alkaline solution for $\mathrm{NH}_{3}$ instead of $\mathrm{NH}_{4}{ }^{+}$.

Additional experiment was done by using the same synthetic wastewater and experimental setup without passing current. The results showed that ammonia concentration decreased from
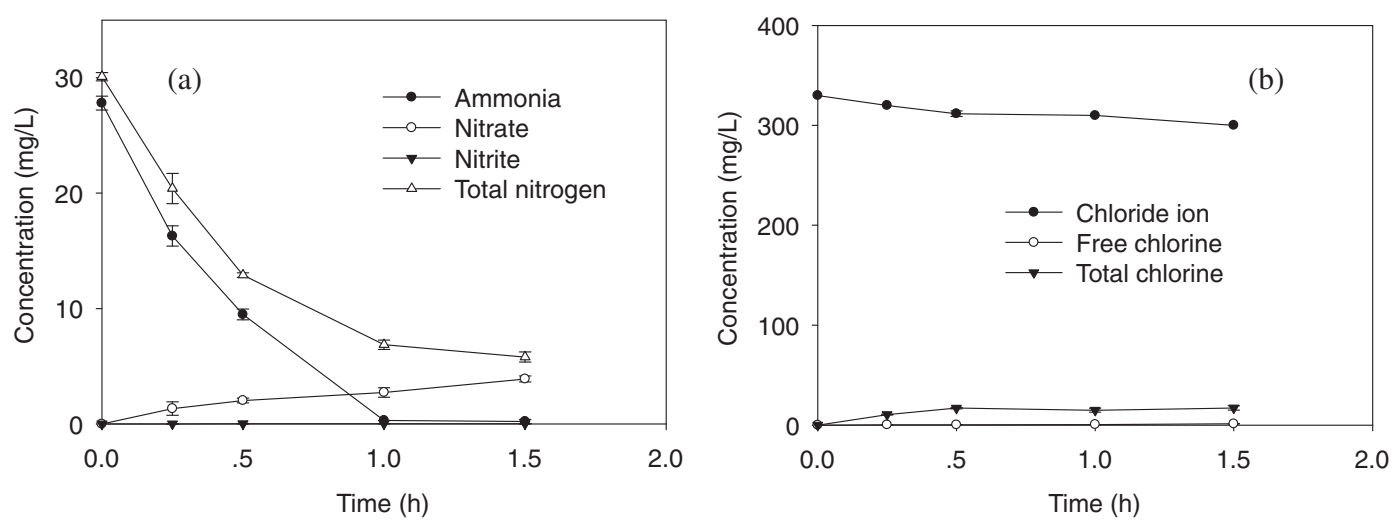

Figure 2. Concentration profiles during electrolysis process of ammonia solution with $330 \mathrm{mg} / \mathrm{L} \mathrm{Cl}^{-}$at $\mathrm{pH} 7.0$ and current density $13.8 \mathrm{~mA} / \mathrm{cm}^{2}$ : (a) different nitrogens and (b) chloro species. 
$29.5 \mathrm{mg} / \mathrm{L}$ to $13.6,12.7,11.6,9.4 \mathrm{mg} / \mathrm{L}$ after $0.25,0.5,1.0,1.5$ hours, respectively. The removal of ammonia without passing current can be ascribed to the adsorption on zeolite. It was obviously that adsorption was very fast during the first $0.25 \mathrm{~h}$ and slowed down when the zeolite become saturated, which was different from the situation of passing current. Compared with the previous experiment, it can be concluded that electrolysis accelerated the removal of ammonia which gave a lower effluent ammonia concentration.

For 2D electrode, many researches proved that direct anode oxidation, indirect oxidation by hydroxyl radicals and hypochlorite acid were the mechanisms for ammonia removal. In chloride mediated system, oxidation-reduction reaction between ammonia and hypochlorite acid was the main passway. The possible reactions were shown in Eqs. (1)-(4): ${ }^{24}$

$$
\begin{array}{ll}
\text { In the anode: } & 2 \mathrm{Cl}^{-} \rightarrow \mathrm{Cl}_{2}+2 \mathrm{e}^{-} \\
\text {In solution: } & \mathrm{Cl}_{2}+\mathrm{H}_{2} \mathrm{O} \rightarrow \mathrm{HClO}+\mathrm{H}^{+}+\mathrm{Cl}^{-} \\
& \mathrm{HClO} \rightarrow \mathrm{ClO}^{-}+\mathrm{H}^{+} \\
\mathrm{HClO} & +(2 / 3) \mathrm{NH}_{4}^{+} \\
& \rightarrow(1 / 3) \mathrm{N}_{2}+\mathrm{H}_{2} \mathrm{O}+(5 / 3) \mathrm{H}^{+}+\mathrm{Cl}^{-} \\
\mathrm{ClO}^{-} & +(2 / 3) \mathrm{NH}_{4}^{+} \\
& \rightarrow(1 / 3) \mathrm{N}_{2}+\mathrm{H}_{2} \mathrm{O}+(2 / 3) \mathrm{H}^{+}+\mathrm{Cl}^{-}
\end{array}
$$

Chlorine gas, which will be easily dissolving in water and forming strong oxidants such as $\mathrm{HClO}, \mathrm{ClO}^{-}$, can be generated on anode surface in the chloride system. Then, ammonia will be oxidized to nitrogen gas. However, not all of the ammonia will be oxidized to nitrogen gas. Some side reactions could occur in the solution as shown in Eqs. (5)-(8). Due to the formation of chloramines and elution of chlorine gas, the chloride concentration decreased after electrolysis for a period of time.

$$
\begin{aligned}
& \mathrm{HClO}+(1 / 4) \mathrm{NH}_{4}^{+} \\
& \quad \rightarrow(1 / 4) \mathrm{NO}_{3}{ }^{-}+(1 / 4) \mathrm{H}_{2} \mathrm{O}+(3 / 2) \mathrm{H}^{+}+\mathrm{Cl}^{-} \\
& \mathrm{NH}_{3}+\mathrm{HClO} \rightarrow \mathrm{NH}_{2} \mathrm{Cl}+\mathrm{H}_{2} \mathrm{O} \\
& \mathrm{NH}_{2} \mathrm{Cl}+\mathrm{HClO} \rightarrow \mathrm{NHCl}_{2}+\mathrm{H}_{2} \mathrm{O} \\
& \mathrm{NHCl}_{2}+\mathrm{HClO} \rightarrow \mathrm{NCl}_{3}+\mathrm{H}_{2} \mathrm{O}
\end{aligned}
$$

In addition, part of the $\mathrm{HClO}, \mathrm{ClO}^{-}$would be transferred to chloride ions on the cathode as shown in Eqs. (9)-(10). Strong oxidants were reduced, leading to the decrease of ammonia oxidation efficiency.

$$
\begin{aligned}
& \mathrm{HClO}+\mathrm{H}^{+}+2 \mathrm{e}^{-} \rightarrow \mathrm{Cl}^{-}+\mathrm{H}_{2} \mathrm{O} \\
& \mathrm{ClO}^{-}+2 \mathrm{H}^{+}+2 \mathrm{e}^{-} \rightarrow \mathrm{Cl}^{-}+\mathrm{H}_{2} \mathrm{O}
\end{aligned}
$$

As for the zeolite packed electrolysis reactor in this experiment, adsorption by zeolite was important at the early stage when free chlorine concentration was low. When electrolysis proceeded, the generated strong oxidants $\mathrm{HClO}, \mathrm{ClO}^{-}$did not only oxidize ammonia in the solution but also regenerate zeolite simultaneously. According to Li Miao's research, ${ }^{13}$ the electrochemical method can regenerate saturated zeolite and the adsorption capacities of regenerated zeolite were recovered almost completely. So combined mechanism of adsorption and electrocatalytic oxidation played an essential role in ammonia removal in the zeolite packed electrolysis reactor.

\subsection{Characterization of the packed zeolite before and after electrolysis}

The XRD patterns of natural zeolite before and after electrolysis were depicted in Fig. 3. Clinoptilolite, quartz and mordenite were found from the profiles, which had no change after electrolysis. Significant increase in the relative intensities at 20.9, 26.7 and $39.5^{\circ}$ $(2 \theta)$ for quartz, at $26.0,30.0^{\circ}(2 \theta)$ for clinoptilolite were observed after electrolysis. This could be ascribed to the loss of impurities on the surface and pore wall of natural zeolite after electrolysis. On the other hand, as can be seen from diffraction patterns of the samples, a new peak at $15.8^{\circ}(2 \theta)$ was observed for clinoptilolite in zeolite after

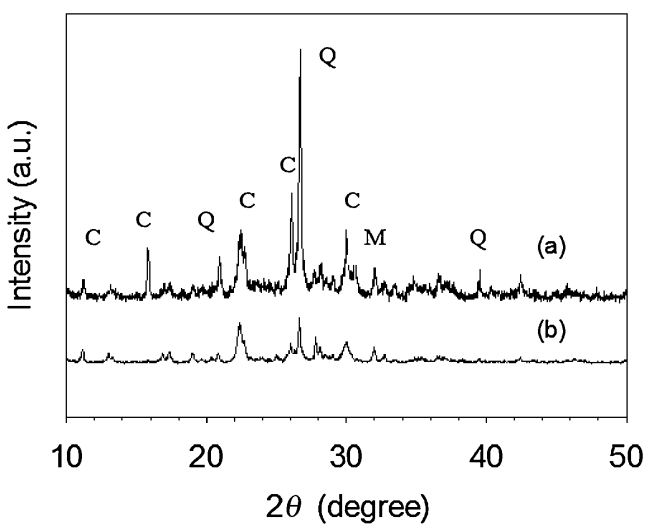

Figure 3. XRD patterns of natural zeolite: (a) after electrolysis; (b) before electrolysis (C: clinoptilolite; Q: quartz; M: mordenite).

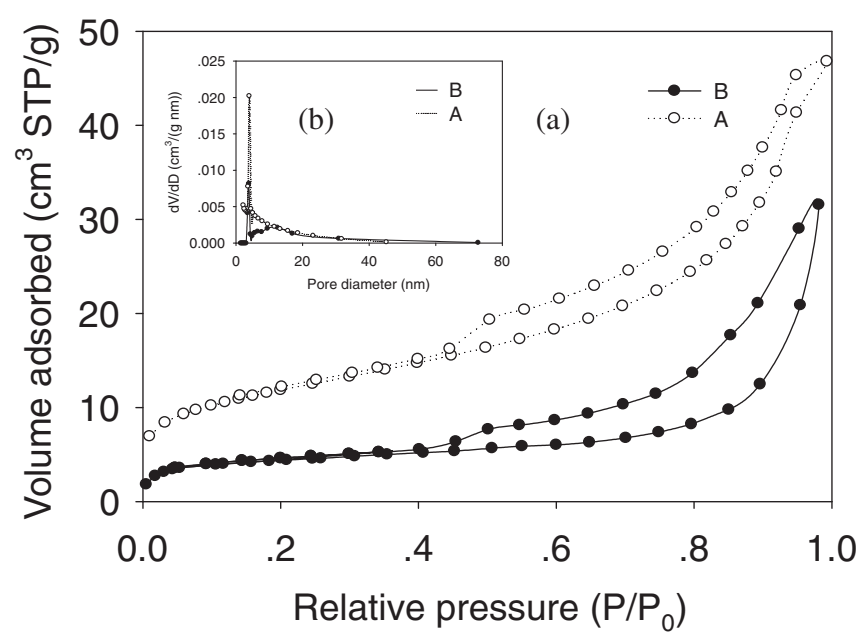

Figure 4. Nitrogen adsorption-desorption isotherms (a) and pore size distribution (b) of the natural zeolite before (B) and after (A) electrolysis.

electrolysis. Based on those results, it can be concluded that there was no transformation in zeolite's main crystalline structure after long time of electrolysis.

The specific surface area and porosity of the natural zeolite were investigated by using nitrogen adsorption and desorption isotherms. As shown in Fig. 4(a), curve A and B showed the nitrogen adsorption-desorption isotherms of the natural zeolite after and before electrolysis, respectively. The isotherms of zeolite before and after electrolysis are types IV according to the Brunauer-DemingDeming-Teller (BDDT) classification, which classified the majority of physisorption isotherms into six types..$^{25}$ As for hysteresis loop, both of them have a $\mathrm{H} 3$ hysteresis loop indicating their pore-size distributions are in mesoporous regions. The BET specific surface areas of the natural zeolite before and after electrolysis were 15.9 and $42.6 \mathrm{~m}^{2} / \mathrm{g}$ respectively, which were calculated from nitrogenadsorption isotherms with data in the relative pressure $\left(\mathrm{P} / \mathrm{P}_{0}\right)$ range of 0.04-0.16. As shown in Fig. 4(b), the corresponding pore-size distributions (PSD) of the zeolite before and after electrolysis were described by curve A and B, respectively. The PSD curve B was bimodal with smaller $(\sim 3.7 \mathrm{~nm})$ and larger $(\sim 18.3 \mathrm{~nm})$ mesopores for zeolite before electrolysis. For zeolite after electrolysis, the PSD curve A was changed to unimodal with smaller $(\sim 4.0 \mathrm{~nm})$ mesopores. By using Barret-Joyner-Halenda desorption method, the average pore volume of zeolite before and after electrolysis can be calculated to be 0.05 and $0.08 \mathrm{~cm}^{3} / \mathrm{g}$, respectively. The significant increase of surface area and pore volume might be caused by two 


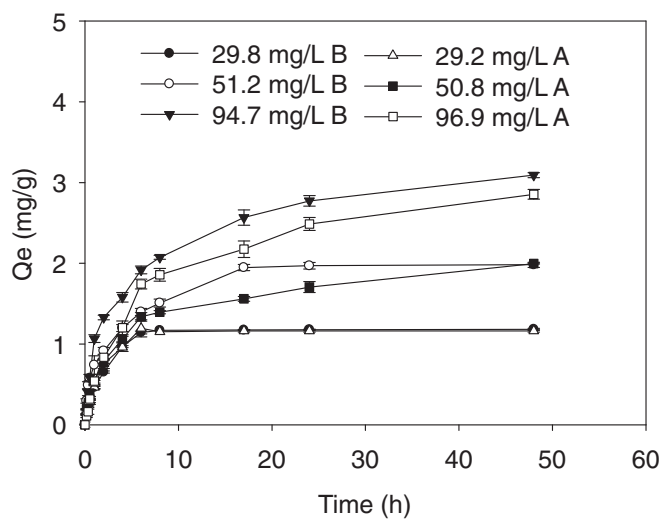

Figure 5. Adsorption of ammonia by zeolite: B represents zeolite before electrolysis; A represents zeolite after electrolysis.
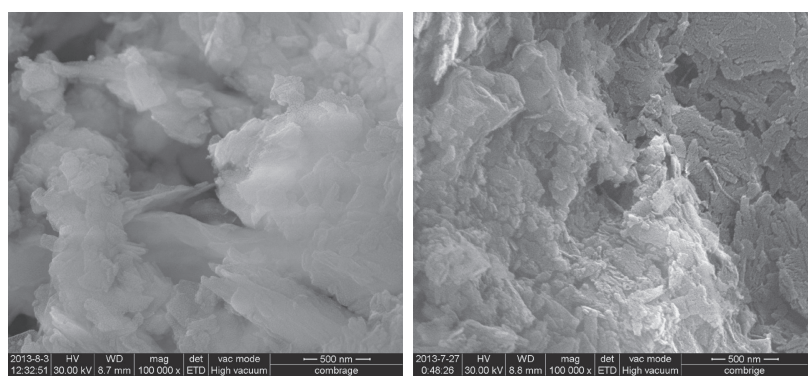

Figure 6. SEM micrographs of zeolite: (left) before electrolysis; (right) after electrolysis.

reasons: one is the removal of impurities through chemical reactions and mechanical action, the other is the formation of new channels/ cavities caused by hydraulic as well as mechanical shearing force during electrolysis.

The adsorption of ammonia on zeolite before (B) and after (A) electrolysis were evaluated with synthetic ammonia solution under batch mode as shown in Fig. 5. Before electrolysis, the adsorption capacities of zeolite were $1.18,1.98$ and $3.09 \mathrm{mg} \mathrm{N} / \mathrm{g}$ zeolite for initial ammonia concentrations of $29.8,51.2$ and $94.7 \mathrm{mg} \mathrm{N} / \mathrm{L}$, respectively. After electrolysis, 1.16, 2.00 and $2.85 \mathrm{mg} \mathrm{N} / \mathrm{g}$ adsorption capacities were observed with the initial ammonia concentrations of $29.2,50.8$ and $96.9 \mathrm{mg} \mathrm{N} / \mathrm{L}$, respectively. No significant change of ammonia adsorption was observed after electrolysis. This phenomenon was not consistent with the obvious increase of surface area. So the adsorption of ammonia on natural zeolite was mainly through the chemical process of ion exchange rather than physical adsorption.

The SEM micrographs in Fig. 6 visually illustrated the same trend obtained by XRD, specific area and porosity analysis. The appearance of zeolite before electrolysis is relatively smooth with clear layer shape. After electrolysis, some fragments chipped off the main body of zeolite. Many fractures, caused by the coaction of hydrodynamic collisions and chemical corrosive effects, appeared on the zeolite surface to make it look more coarse, and thus reflected the generation of new channels and cavities, which lead to increase the surface area and pore volume. However, the laminated structure of zeolite kept unchanged, which was in accordance with the XRD results.

\section{Conclusions}

Zeolite packed electrolysis reactor with $\mathrm{RuO}_{2} / \mathrm{Ti}$ as anode and stainless steel as cathode could enhance ammonia removal rate significantly in wastewater treatment. The mechanism for ammonia removal by zeolite packed electrolysis reactor included the combined action of ion-exchange, electrochemical oxidation and simultaneously electrocatalytic regeneration of zeolite. Nitrite, nitrate, chloramines and gaseous products were found to be main products of ammonia oxidation. After electrolysis, the main components and crystalline structure of zeolite had no change, the surface area and pore volume increased significantly, which might be caused by the removal of impurities and formation of new channels/cavities during electrolysis. However, the adsorption capacity of zeolite for ammonia kept almost the same before and after electrolysis.

\section{Acknowledgments}

The authors would like to thank the National Natural Science Foundation of China (No. 51208299), Science \& Technology Commission of Shanghai Municipality (No. 11JC1408700), and "Chen Guang" project supported by Shanghai Municipal Education Commission and Shanghai Education Development Foundation (No. 11CG52) for funding support.

\section{References}

1. G. Perez, R. Ibanez, A. M. Urtiaga, and I. Ortiz, Chem. Eng. J., 197, 475 (2012).

2. L. Lin, S. h. Yuan, J. Chen, and Z. Xu, J. Hazard. Mater, 161, 1063 (2009).

3. L. Zhang, Y. W. Lee, and D. Jahng, J. Hazard. Mater., 199-200, 362 (2012).

4. X. Quan, C. Ye, Y. Xiong, and J. Xiang, J. Hazard. Mater., 178, 326 (2010).

5. K. Saltali, A. Sari, and M. Aydin, J. Hazard. Mater, 141, 258 (2007).

6. D. Rajkumar and K. Palanivelu, J. Hazard. Mater., 113, 123 (2004).

7. X. Zhu, M. A. Nanny, and E. C. Butler, Water Res., 42, 2736 (2008).

8. T. Ochiai and A. Fujishima, J. Photochem. Photobiol. C: Phytochem. Rev., 13, 247 (2012).

9. H. Huang, X. Xiao, B. Yan, and L. Yang, J. Hazard. Mater, 175, 247 (2010).

10. T. C. Jorgensen and L. R. Weatherley, Water Res., 37, 1723 (2003).

11. R. M. Burgess, M. M. Perron, M. G. Cantwell, and K. T. Ho, Envion. Contam. Tox, 47, 440 (2004).

12. A. A. Halim, H. A. Aziz, M. A. M. Johri, and K.S. Ariffin, Desalination, 262, 31 (2010).

13. X. Lei, M. Li, Z. Zhang, and W. Bai, J. Hazard. Mater, 169, 746 (2009).

14. M. Zhou, W. Wang, and M. Chi, Bioresour. Technol., 100, 4662 (2009).

15. H. Zhang, Y. Li, X. Wu, and Y. Zhang, Waste Manage,, 30, 2096 (2010).

16. A. M. Polcaro, S. Palmas, F. Renoldi, and M. Mascia, Electrochim. Acta, 46, 389 (2000).

17. Y. Xiong, C. He, H. T. Karlsson, and X. Zhu, Chemosphere, 50, 131 (2003).

18. L. Xu, H. Zhao, S. Shi, G. Zhang, and J. Ni, Dyes Pigm., 77, 158 (2008).

19. X. Zhu, J. Ni, X. Xing, H. Li, and Y. Jiang, Electrochim. Acta, 56, 1270 (2011).

20. W. Kong, B. Wang, H. Ma, and L. Gu, J. Hazard. Mater, 137, 1532 (2006).

21. W. Liu, Z. Ai, and L. Zhang, J. Hazard. Mater, 243, 257 (2012).

22. APHA, Standard Methods for the Examination of Water and Wastewater, 20th ed., American Public Health Association, Washington D.C. (1998).

23. R. M. G. d. Lima, G. R. d. S. Wildhagen, J. W. S. D. d. Cunha, and J. C. Afonso, J. Hazard. Mater., 161, 1560 (2009).

24. E. Lacasa, J. Llanos, P. Cañizares, and M. A. Rodrigo, Chem. Eng. J., 184, 66 (2012).

25. K. S. W. Siong, D. H. Everett, R. A. W. Haul, L. Moscou, and R. A. Pierotti, Pure Appl. Chem., 57, 603 (1985). 